\title{
Models of care for traumatically injured patients at trauma centres in British Columbia: variability and sustainability
}

\author{
Benjamin Tuyp, $\mathrm{MD}^{*}$; Kasra Hassani, $\mathrm{PhD}, \mathrm{MPH}^{\dagger}$; Lisa Constable, $\mathrm{BScN}, \mathrm{MN}^{\dagger}$; Joseph Haegert, $\mathrm{MD}^{*}$
}

\section{ABSTRACT}

Background: Successful trauma systems employ a network of variably-resourced hospitals, staffed by experienced providers, to deliver optimal care for injured patients. The "model of care" - the manner by which inpatients are admitted and overseen, is an important determinant of patient outcomes.

Objectives: To describe the models of inpatient trauma care at British Columbia's (BC's) ten adult trauma centres, their sustainability, and their compatibility with accreditation guidelines.

Methods: Questionnaires were distributed to the trauma medical directors at BC's ten Level I-III adult trauma centres. Follow-up semi-structured interviews clarified responses.

Results: Three different models of inpatient trauma care exist within BC. The "admitting trauma service" was a multidisciplinary team providing exclusive care for injured patients. The "on-call consultant" assisted with Emergency Department (ED) resuscitation before transferring patients to a non-trauma admitting service. The single "short-stay trauma unit" employed on-call consultants who also oversaw a 48-hour short-stay ward.Both level I trauma centres utilized the admitting trauma service model (2/2). All Level II sites employed an on-call consultant model (3/3), deviating from Level II trauma centre accreditation standards. Level III sites employed all three models in similar proportions. None of the on-call consultant sites believed their current care model was sustainable. Inadequate compensation, insufficient resources, and difficulty recruiting physicians were cited barriers to sustainability and accreditation compliance.

Conclusions: Three distinct models of care are distributed inconsistently across BC's Level I-III trauma hospitals. Greater use of admitting trauma service and short-stay trauma unit models may improve the sustainability and accreditation compliance of our trauma system.

\section{RÉSUMÉ}

Introduction: Les systèmes de soins en traumatologie qui donnent de bons résultats reposent sur un réseau d'hôpitaux dotés de diverses ressources et d'un personnel expérimenté afin de permettre une prestation optimale de soins aux blessés. Le " modèle de soins ", c'est-à-dire la manière dont les personnes sont admises et surveillées, est un déterminant important de l'évolution de l'état de santé.

Objectifs: L'étude visait à décrire les modèles de soins appliqués dans 10 centres de traumatologie pour adultes en Colombie-Britannique (C.-B.) et à examiner la durabilité des différents modes de prestation et le respect des lignes directrices relatives à l'agrément.

Méthode: Un questionnaire a été envoyé aux directeurs médicaux de 10 centres de traumatologie pour adultes, de niveau I à III, en C.-B. Des entrevues semi-structurées de suivi ont permis de clarifier des réponses.

Résultats: II existe trois modèles de soins en traumatologie en C.-B. : le " service d'admission en traumatologie ", qui consiste en une équipe pluridisciplinaire vouée à la prestation exclusive de soins aux blessés; le " consultant de garde ", qui travaille en collaboration avec une équipe de réanimation du service des urgences avant le transfert des patients vers un service d'admission non spécialisé en traumatologie; et l'" unité de traumatologie de courte durée ", service spécialisé en la matière, dont la prestation de soins est assurée par des consultants de garde qui supervisent également un service de soins de courte durée de 48 heures. Les centres de traumatologie de niveau I, au nombre de deux, appliquent le modèle du " service d'admission en traumatologie " (2/2). Tous les centres de niveau II appliquent le modèle du "consultant de garde " (3/3), ce qui contrevient aux normes d'agrément des centres de traumatologie de niveau II. Quant aux centres de niveau III, ils appliquent les trois modèles dans des proportions comparables. Aucun des directeurs des centres appliquant le modèle du consultant de garde ne croyait en la durabilité de ce mode de prestation. Une rétribution insuffisante, le manque de ressources et la difficulté de trouver des médecins sont tous des facteurs considérés comme des obstacles à la durabilité et au respect des normes d'agrément.

Conclusions: Les trois modèles de soins ne sont pas répartis de manière uniforme dans les centres de traumatologie de niveau I à III, en C.-B. Le recours plus fréquent au modèle du

From the *Department of Emergency Medicine, University of British Columbia, Vancouver, BC; and the tRoyal Columbian Hospital Trauma Program, Fraser Health Authority, New Westminster, BC.

Correspondence to: Joseph Haegart, FH Trauma Program, 260 Sherbroooke St., Office M33, New Westminster, BC V3L 3M2; Email: Joe.Haegert@fraserhealth.ca 
service d'admission en traumatologie et à celui de l'unité de traumatologie de courte durée pourrait améliorer la durabilité du système de soins en traumatologie et la conformité aux normes d'agrément.
Keywords: trauma system, trauma centre, trauma service, patient care, model of care

\section{INTRODUCTION}

Traumatic injuries place a high toll on the lives and pocketbooks of Canadians. Within British Columbia (BC), one-half million ED visits, 35,000 hospitalizations, and 2000 deaths were attributed to injury in 2010 at an estimated cost of $\$ 3.7$ billion. ${ }^{1}$

Modern trauma systems comprise several hospitals stratified by resource availability and linked through field triage and inter-facility transfer criteria, all designed to match injured patients to the best facility able to meet their needs. Accreditation Canada is responsible for credentialing trauma centres across the country. Hospitals are assigned a Level I through $\mathrm{V}$ based on the resource and subspecialty availability at each site. The provincial adult trauma system of $\mathrm{BC}$ is built around ten hospitals: two Level I, three Level II, and five Level III sites. Level I and II sites provide definitive care, and lower level centres initiate injury stabilization prior to transfer. ${ }^{2}$ Although the accreditation level of a hospital dictates the scope of treatment available at a particular site, many factors influence the quality of patient care. The "model of care," the manner by which patients are admitted, overseen, and handed over, is an important determinant of good patient outcomes. A recent review attributed $34 \%$ of patient safety-related in-hospital deaths to deficiencies attributable to models of care, including inadequate handover, poor patient observation, and failure to recognize patient deterioration. ${ }^{3}$

A variety of models of care for admitted trauma patients have been described in medical literature. At larger centres, a single trauma service would generally oversee all injured patients, and at smaller sites, oversight is provided by a variety of surgical and hospitalist services depending on injury pattern. ${ }^{4-7}$ However, although national accreditation guidelines endorse this distribution of care models, the real-world practice remains unknown; available existing literature has examined only individual, almost exclusively Level I trauma hospitals. Given the influence that the model of patient oversight has upon the management of injured patients, we sought to describe the various models of care currently operating within our provincial trauma system. To determine the ideal model of care for each of our variably sized centres, we explored the sustainability of each model and investigated its compatibility with the standards recommended for each trauma accreditation level.

\section{METHODS}

Prior to this study, meetings among stakeholders at trauma centres in $\mathrm{BC}$ revealed an inadequate understanding of the variety of models of care in existence. A study group was convened, and a questionnaire was developed in consultation with regional and provincial trauma medical directors. The study protocol was approved by the Fraser Health Information Privacy and Security Office. Informed consent was obtained from all study participants. In November 2015, an electronic survey was distributed by email to the medical directors of trauma at ten receiving adult trauma centres in BC. The 39-item questionnaire explored characteristics of models of care for injured patients, including the specialty and composition of the admitting team, service intervals, and additional clinical responsibilities. The survey scrutinized determinants of the existing model and barriers to its overall sustainability, specifically asking if site directors thought their trauma program was sustainable for $>5$ years in its current form. The model of care for each care was examined alongside the relevant criteria of the 2014 Accreditation Canada Trauma Distinction Centre Standards to establish guideline compliance. ${ }^{2}$ Follow-up telephone interviews with respondents were built upon survey results to clarify responses.

\section{RESULTS}

All ten sites returned completed surveys and responded to telephone follow-ups. With one exception, the oversight of admitted patients at these centres conformed to one of two models of care that are hereafter referred to as the "admitting trauma service" and 


\begin{tabular}{|c|c|c|c|}
\hline Model of care & Admitting trauma service & On-call consultant & Short-stay trauma unit \\
\hline Patient care role & $\begin{array}{l}\text { Attending physician from time of } \\
\text { "activation" or EP-initiated ED } \\
\text { consultation until discharge from } \\
\text { hospital or transfer to hospitalist } \\
\text { service }\end{array}$ & $\begin{array}{l}\text { Attending physician from time of } \\
\text { EP-initiated ED consultation until } \\
\text { transfer to admitting service or } \\
\text { another hospital }\end{array}$ & $\begin{array}{l}\text { Attending physician from time of EP- } \\
\text { initiated ED consultation until } \\
\text { transfer to admitting service } \\
\text { (unless short-stay unit patient) or } \\
\text { another hospital }\end{array}$ \\
\hline Admitting service & $\begin{array}{l}\text { Trauma or critical care (with trauma } \\
\text { following in consultation and } \\
\text { subsequent transfer to trauma) }\end{array}$ & $\begin{array}{l}\text { Critical care, surgical team } \\
\text { overseeing the most severely } \\
\text { injured organ system, general } \\
\text { surgery, or hospitalist (for non- } \\
\text { operative patients) }\end{array}$ & $\begin{array}{l}\text { For patients with anticipated hospital } \\
\text { length of stay }<48 \mathrm{hrs,} \text { admitted } \\
\text { under trauma short-stay unit, } \\
\text { otherwise admitted as per on-call } \\
\text { consultant model }\end{array}$ \\
\hline Team composition & $\begin{array}{l}\text { Residents, fellows, and trauma } \\
\text { nurses, led by an emergency } \\
\text { physician, general surgeon, or } \\
\text { trauma surgeon }\end{array}$ & $\begin{array}{l}\text { Single emergency physician or } \\
\text { general practitioner }\end{array}$ & $\begin{array}{l}\text { Single emergency physician or } \\
\text { general practitioner }\end{array}$ \\
\hline $\begin{array}{l}\text { Attending physician } \\
\text { service duration }\end{array}$ & $1 / 2$ or 1 week & 12 or 24 hours & 24 hours \\
\hline $\begin{array}{l}\text { Cohorting of patients } \\
\text { into single ward }\end{array}$ & Yes (ICU a separate cohort) & No & Yes (short-stay trauma unit only) \\
\hline
\end{tabular}

"on-call consultant" models. The third novel model was labelled the "short-stay trauma unit" (Table 1).

The "admitting trauma service" was an admitting service led by an emergency physician, a general surgeon, or a trauma surgeon. All these services employed a full-time trauma nurse to assist with the patient care process, and all but one rotated residents or fellows through the service. Except for time spent within a closed intensive care unit, this team remained the admitting and most responsible service from the time of consultation or "activation" (rapid in-person consultation at any time, triggered by anatomic, mechanistic, or physiologic injury criteria) in the emergency department (ED) until the patient had progressed beyond the acutely injured period and was discharged from the hospital or transferred to a hospitalist service. The service interval for the attending trauma physician lasted one-half to 1 week, during which time their clinical responsibilities were restricted to the daily care of admitted patients, re-assessing recently discharged individuals at once-weekly trauma clinics, and assessing new admissions during the daytime and a portion of the evening hours. The attending physician's extraneous clinical responsibilities (associated with their usual ED or elective surgical practices) were minimized to the greatest extent possible to ensure prompt, attentive trauma care.

The "on-call consultant" model comprised an emergency physician or a general practitioner available to provide supplementary care for trauma patients in the ED. On-call consultants were "called in" at any time and at the discretion of the attending emergency physician. Common scenarios for call in included trauma "activation," multiple casualties, pre-arrival paramedic notification of major trauma, or the anticipated need for multiple ED procedures. The on-call consultant attended to the injured patients only while they were in the ED until they were transferred to a higher level of care or admitted by another service. These other services could be the intensivist for the severely injured patient, a surgical service overseeing the most significantly injured organ system, or the hospitalist for all non-surgical patients. The on-call consultant service interval spanned 12-24 hours, during which time additional clinical duties were at least tolerated or at the quieter centres even encouraged. Examples of these responsibilities included conducting one's personal office clinic or serving as an attending physician in a different ED.

The "short-stay trauma unit" model employed emergency physicians or general practitioners who were available to provide supplementary care in the ED in the same fashion as the on-call consultant model. However, these physicians also attended to a short-stay trauma unit, which admitted a cohort of injured patients whose hospital length of stay was estimated to be $\leq 48$ hours. Similar to the on-call consultant model, 


$\begin{aligned} & \text { Table 2. Distribution of trauma models of care within } \\
& \text { different levels of trauma centres }\end{aligned}$
\begin{tabular}{ll} 
Trauma level & Trauma models of care used \\
\hline Level I & Admitting trauma service (2/2) \\
Level II & On-call consultant (3/3) \\
Level III & Admitting trauma service (2/5), on-call consultant \\
& $(2 / 5)$, or short-stay trauma unit $(1 / 5)$
\end{tabular}

various other services would admit from the ED those trauma patients with longer anticipated stays, as well as assuming care at the 48-hour mark for those patients whose hospital discharge had been unexpectedly delayed. Trauma physicians at this site remained on-call for 24 hours, during which time they were expected to round on those patients admitted to the short-stay trauma unit, as well as the adjacent observation unit (which housed uncomplicated medical patients requiring an admission of $\leq 48$ hours). Additional non-trauma, non-observation unit clinical responsibilities were discouraged while on-call.

The distribution of the three models by trauma level designation was as follows: all Level I trauma centres utilized the admitting trauma service model (2/2), and all Level II centres employed an on-call consultant (3/3). Level III centres relied upon the admitting trauma service (2/5), on-call consultant (2/5), and shortstay trauma unit models (1/5) (Table 2). If arranged by annual BC Trauma Registry case volume (injured patients aged $>15$ years who required $\geq 48$ hours of hospitalization or dying as a result of their injuries), we discovered that sites with $>1000$ cases per year all utilized admitting trauma services (2/2), those with 5001000 cases per year employed both admitting trauma services (1/4) and on-call consultants (3/4), and those with $<500$ cases per year operated all three models of care: admitting trauma service (1/4), on-call consultant $(2 / 4)$, or short-stay trauma unit (1/4) (Table 3$){ }^{8}$

Only one-half $(5 / 10)$ of the medical directors of trauma centres in BC believed that their current model of care was sustainable in its existing form, with significant discordance depending on the type of model currently in situ. All medical directors (4/4) of the admitting trauma services and short-stay trauma unit (1/1) sites believed that these sites were sustainable beyond 5 years. On the contrary, all medical directors of on-call consultant facilities either did not believe their facilities were sustainable (4/5) or "did not know" (1/5). The most commonly reported barriers to program
Table 3. Distribution of trauma models of care separated by patient load

\begin{tabular}{|c|c|}
\hline $\begin{array}{l}\text { Patient volume (number of } \\
\text { trauma registry cases per year) }\end{array}$ & Models of care \\
\hline$>1000$ & Admitting trauma service $(2 / 2)$ \\
\hline $500-1000$ & $\begin{array}{l}\text { Admitting trauma service }(1 / 4) \\
\text { or on-call consultant }(3 / 4)\end{array}$ \\
\hline$<500$ & $\begin{array}{l}\text { Admitting trauma service }(1 / 4) \text {, on- } \\
\text { call consultant }(2 / 4) \text {, or short-stay } \\
\text { trauma unit }(1 / 4)\end{array}$ \\
\hline
\end{tabular}

sustainability were inadequate compensation (6/10); limited access to hospital resources such as operating rooms, beds, and consultants (6/10); and difficulty in recruiting new medical staff to their site (2/10). All trauma medical directors of on-call consultant centres desired to transition toward an admitting trauma service but reported difficulties securing physician reimbursement.

\section{DISCUSSION}

This study describes the three models by which admitted injured patients are overseen at ten Level I to III adult trauma centres in BC: the admitting trauma service, on-call consultant, or short-stay trauma unit. The distribution of these models was not completely explained by the accreditation level, and at some centres, the model in situ did not satisfy accreditation standards.

\section{Level I and II sites}

Both Level I trauma hospitals in the province, each treating $>1000$ BC Trauma Registry cases annually, utilized an admitting trauma service. Numerous retrospective cohort studies have supported this concept as the ideal model for tertiary centres: up to an $8 \%$ mortality reduction, and reductions in-hospital length of stay, per-patient cost, and complications have been demonstrated following the adoption of an admitting trauma service (if it was replacing a model in which trauma patients were admitted by the general surgery service). ${ }^{4,6,9,10}$ However, these findings also challenge the reliance upon on-call consultant models of care at all Level II sites used in our trauma system. Two of these sites are the definitive trauma centres within their geographic region and health authority, with the closest neighbouring Level I site being 90-250 kilometres away. 
The patient volume, geographic isolation, and capability of these centres make them comparable to sites that have demonstrated improved patient outcomes with the implementation of an admitting trauma service. ${ }^{11}$ In fact, these on-call consultant sites fail to satisfy current credentialing guidelines, as Accreditation Canada recommends that all Level II centres provide "comprehensive inpatient trauma services ... [utilizing an] interdisciplinary team ... [that] manages trauma patients on a dedicated trauma unit or a clustered area," a definition not consistent with that of the on-call consultant models currently operating within our trauma system. ${ }^{2}$

Reassuringly, respondents at all Level II sites reported ongoing efforts to initiate an admitting trauma service model of care and thereby satisfy accreditation standards, as none of them believed their current on-call consultant model was sustainable. However, cited barriers to this transition included insufficient funds for program operation and staff reimbursement, as well as insufficient access to necessary hospital beds. These difficulties are evidenced by one Level II site that continued to employ an on-call consultant model at the time of publication despite initially planning an admitting trauma service start date of January 2016.

Inadequate funding was a commonly cited impediment to establishing an admitting trauma service. The inpatient care component of this model incurs additional physician duty hours and often necessitates the employment of a trauma nurse practitioner or case manager to ensure continuity of care. However, these ancillary positions have been independently shown to improve patient satisfaction and reduce the length of stay by up to $11 \% .^{12}$ Furthermore, retrospective cost analyses have suggested that overall per-patient hospital spending is up to $38 \%$ lower with an admitting trauma service, as compared with other models of care. ${ }^{6}$ Therefore, the upfront funds required for model transition might be recuperated over time. Nevertheless, if an admitting trauma service remained fiscally impossible, it stands to reason that an on-call consultant or short-stay trauma unit model may still be preferable to historic practices (which involve transferring care directly from the emergency physician to the surgical service overseeing the most severely injured organ system). These two models have the benefit of providing trauma-centred, multi-system oversight at least in the ED or during the first 48-hour portion of the hospital stay.

\section{Level III sites}

Within the Level III centres, both the on-call consultant and admitting trauma service models were equally common (2/5), and a unique "short-stay trauma unit" was also in situ (1/5). The ideal model of care for Level III centres remains uncertain, a result of insufficient evidence. Except for the 2010 study by Daniel et al. $^{11}$ at the Level III Medical Center Hospital demonstrating a $33 \%$ reduction in the mortality of severely injured patients after the implementation of an admitting trauma service, all other studies that demonstrated improved patient outcomes with an admitting trauma service have been conducted in Level I or II facilities. However, a 2010 study by Hameed et al. ${ }^{13}$ suggested that geography may demand that some Level III centres emulate the care-and perhaps the model of care-of Level I and II hospitals, as $22 \%$ of Canadians and $24.3 \%$ of British Columbians reside outside the 1-hour road travel catchments of Level I and II centres, making them dependent upon rural and remote centres for initial stabilization. In summary, the limited data suggests that Level III trauma centres, particularly those who are geographically isolated from Level I and II sites, might benefit from an admitting trauma service model of care.

If organized by patient volume, we discovered that the highest-volume Level III centres in BC employed an admitting trauma service, while low-volume centres had an on-call consultant and the median sites utilized a short-stay trauma unit. ${ }^{14}$ However, differences in patient volumes between sites are subtle enough to cast doubt on its significance in determining the model of care. Indeed, admissions at the short-stay trauma unit sites outnumbered those at an admitting trauma service site 4 years out of the last 6 years. ${ }^{8,14}$ Interestingly, both Level III admitting trauma service sites belonged to a regional health authority employing a Level I admitting trauma service. It is possible that transitioning to an admitting trauma service at an affiliated hospital is more attractive than the de novo creation of such a service within a hospital network because of the following: satisfaction and comfort with a known model, incremental cost savings by adding to an existing model rather than starting a new one, or fewer barriers to implementing a familiar model.

Interestingly, the short-stay trauma unit site was the only centre without an admitting trauma service that indicated this model of care was sustainable for the 
next 5 years. To our knowledge, this is the first time this model of care has been described for injured patients. The short-stay trauma unit is an attractive and likely more sustainable alternative than the on-call consultant model for small centres for several reasons. First, it allows a greater number of patients such as those who are admitted to the short-stay trauma unit to receive care from physicians devoted to trauma. The size of this subgroup is not inconsequential, as Level III sites care for a relatively less injured cohort that remains following the transfer of more severely injured patients to higher level centres. A study of two rural hospitals in Kentucky noted that the length of stay for trauma patients was on average 2.3 and 3.8 days. ${ }^{15}$ Second, the creation of a dedicated trauma unit may facilitate the retention of some injured patients at smaller centres, specifically the $24 \%$ of patients transferred to Level I trauma centres who are discharged home within 48 hours without ever requiring surgical intervention. ${ }^{16}$ Multiple studies have demonstrated that Level III centres can provide safe, definitive care for this less injured population with no significant difference in outcomes, lower per-patient costs, and improved convenience to patients and their families. ${ }^{17,18}$

\section{Sustainability}

All medical directors of admitting trauma service and short-stay trauma unit sites believed that their sites were sustainable for $>5$ years in their current form, but none of the trauma medical directors at the five on-call consultant sites believed that their model was sustainable. Inadequate remuneration, difficulty in recruiting additional on-call physicians, limited access to hospital resources such as beds and consultants, and consulting services are reluctant to admit some nonoperative injured patients were all cited as barriers to the sustainability of their current model of care. Respondents from on-call consultant sites unanimously believed that adopting an admitting trauma service would alleviate these difficulties. With respect to physician remuneration, improvements have been noted following the transition to an admitting trauma service, but only if accompanied by strategies to improve diagnostic and fee coding. ${ }^{6}$ We were unable to find any research examining the effects of an admitting trauma service on physician recruitment or hospital resource access.

\section{CONCLUSIONS}

The ten adult trauma centres in BC utilized three different models of overseeing admitted injured patients: the admitting trauma service, the on-call consultant, and the short-stay trauma unit models of care. The first system was employed at both Level I sites and several of their affiliated Level III sites and was universally believed to be sustainable. The on-call consultant model, found at all Level II and several Level III hospitals, was not sustainable at any site, and it further precluded Level II centres from satisfying accreditation guidelines. If financial and resource barriers can be overcome, implementing admitting trauma services at Level I and II sites, along with either admitting trauma services or short-stay trauma units at Level III centres, would improve the sustainability and accreditation compliance of our provincial trauma system.

Acknowledgements: The authors would like to acknowledge Dr. David Evans for inspiring this project and the BC Trauma Registry data analysts, Joanna Szpakowski and Karli Gamble, for their assistance. This research received no specific grant from any funding agency, commercial entity, or not-for-profit sector.

Competing interests: None declared.

\section{REFERENCES}

1. Rajabali F, Ibrahimova A, Barnett B, Pike I. Economic Burden of Injury in British Columbia. Vancouver: BC Injury Research and Prevention Unit; 2015, Available at: http://www.injur yresearch.bc.ca/wp-content/uploads/2015/08/BCIRPU-EB2015.pdf.

2. Accreditation Canada, Trauma Association of Canada. Trauma Distinction Centre Standards. Ottawa: Trauma Association of Canada; 2014.

3. Donaldson LJ, Panesar SS, Darzi A. Patient-safety-related hospital deaths in England: thematic analysis of incidents reported to a national database, 2010-2012. PLoS Med 2014;11(6):1-001667.

4. Simons R, Eliopoulos V, Laflamme D, Brown DR. Impact on process of trauma care delivery 1 year after the introduction of a trauma program in a provincial trauma center. 7 Trauma-Injury Infect Crit Care 1999;46(May):811-6.

5. Roettger RH, Taylor SM, Youkey JR, Blackhurst DW. The general surgery model: A more appealing and sustainable alternative for the care of trauma patients. Am Surg 2005;71 (8):633-9.

6. Davis KA, Cabbad NC, Schuster KM, et al. Trauma team oversight improves efficiency of care and augments clinical and economic outcomes. 7 Trauma 2008;65(6):1236-42.

7. Salottolo K, Slone DS, Howell P, et al. Effects of a nonsurgical hospitalist service on trauma patient outcomes. Surgery. 2009;145(4):355-61. 
8. Gezer R, Thakore J, McMillan J, Robinson S. Trauma Services BC: Annual Data Summary Report - FY 2014/2015. Vancouver: Provincial Health Services Authority; 2015.

9. Ursic C, Curtis K, Zou Y, Black D. Improved trauma patient outcomes after implementation of a dedicated trauma admitting service. Injury 2009;40(1):99-103.

10. Abernathy JH, McGwin G Jr, Acker JE 3rd, Rue LW 3rd. Impact of a voluntary trauma system on mortality, length of stay, and cost at a level I trauma center. Am Surg 2002; 68(2):182-92.

11. Daniel CO, West TA, Craig-Blanco PS, Myers JG, Stewart RM. Full time trauma service leads to improved Level III trauma center outcomes. Am 7 Surg 2010;200(6):734-9.

12. Collins N, Miller R, Kapu A, et al. Outcomes of adding acute care nurse practitioners to a Level I trauma service with the goal of decreased length of stay and improved physician and nursing satisfaction. 7 Trauma Acute Care Surg 2014;76(2):353-7.

13. Hameed SM, Schuurman N, Razek T, et al. Access to trauma systems in Canada. 7 Trauma 2010;69(6):1350-61.
14. Jones C, Evans D, Thakore JD. Trauma Services BC: Executive Summary 2014. Vancouver; 2014. Available at: http://www.phsa.ca/our-services-site/Documents/TSBC ExecutiveSummary-2014.pdf.

15. Richardson JD, Cross T, Lee D, et al. Impact of level III verification on trauma admissions and transfer: comparisons of two rural hospitals. 7 Trauma 1997;42(3):493-502; Available at: http://ovidsp.ovid.com/ovidweb.cgi? T=JS\&PAGE=reference $\& \mathrm{D}=$ med4\&NEWS $=\mathrm{N} \& \mathrm{AN}=9095118$.

16. Sorensen MJ, von Recklinghausen FM, Fulton G, Burchard KW. Secondary overtriage: the burden of unnecessary interfacility transfers in a rural trauma system. FAMA Surg 2013;148(8):763-8.

17. Arthur M, Newgard CD, Mullins RJ, et al. A populationbased survival assessment of categorizing level III and iv rural hospitals as trauma centers. 7 Rural Health 2009;25(2):182-8.

18. Newgard C, Staudenmayer C, Hsia R, et al. The cost of overtriage: more than one-third of low-risk injured patients were taken to major trauma centers. Heal Aff (Millwood) 2013;32(9):1591-9. 